\title{
GW23-e0673 PREVENTION OF CONTRAST-INDUCED NEPHROPATHY WITH ASCORBIC ACID
}

doi:10.1136/heartjnl-2012-302920l.32

Ruirui Li, Hui Chen. BeiJing Friendship Hospital, Capital Medical University, Cardiovascular Center

Objectives A single-center prospective randomised controlled trials was performed, 149 patients were divided randomly into control group ( $n=78$, receiving only $0.9 \%$ sodium chloride solution for routine hydration) and intervention group ( $n=71$, based on routine hydration receiving vitamin $\mathrm{C}$ intravenous infusion, $3.0 \mathrm{~g}, 2-4 \mathrm{~h}$ before operation, and oral vitamin $\mathrm{C}, 1.0 \mathrm{~g}$, on day 1,2 , respectively, after operation). The total dosage of intravenous and oral vitamin was $5.0 \mathrm{~g}$. The renal function and the occurrence of adverse cardiac events were observed after operation.

Results There was no difference between ascorbic acid group and control group in mean peak increase in serum creatinine measured within $48 \mathrm{~h}$ after coronary angiography, the primary study end point $(0.11 \pm 0.18$ vs $0.08 \pm 0.80 \mathrm{mg} / \mathrm{dl}, \mathrm{p}=0.07)$. The incidence of contrast-induced nephropathy, a secondary end point defined as increase of either $\geq 25 \%$ or $\geq 0.5 \mathrm{mg} / \mathrm{dl}$ in serum creatinine, was $6.41 \%$ in ascorbic acid-treated patients $(5 / 78)$ and $5.63 \%$ in control group patients $(4 / 71)$, a nonsignificant difference $(p=0.73)$. There were also no differences between the 2 groups in the in hospital clinical outcomes and time of hospital stay.

Conclusions Ascorbic acid pretreatment for short-term at high dose do not prevent the decline in renal function after administration of contrast medium in patients with baseline renal insufficiency undergoing coronary angiography. 